\title{
Whole-genome analysis of natural interspecific recombinant between bovine alphaherpesviruses 1 and 5
}

\author{
Sonia Alejandra Romera ${ }^{1, a, b, g}$, Ruben Perez ${ }^{1, c}$, Ana Marandino ${ }^{c}$, Rocio LuciaTau ${ }^{\text {a }}$, \\ Fabricio Campos ${ }^{\mathrm{d}}$, Paulo Michel Roehe ${ }^{\mathrm{e}}$, Etienne Thiry ${ }^{\mathrm{f}}$, Silvina Soledad Maidana ${ }^{\mathrm{a}, \mathrm{g}, "}$ \\ ${ }^{\text {a }}$ Instituto de Virología e Innovaciones Tecnológicas IVIT (INTA-CONICET), Castelar, Buenos Aires, Argentina \\ ${ }^{\mathrm{b}}$ Cátedra de Inmunología, Universidad del Salvador, Provincia de Buenos Aires, Argentina \\ ${ }^{\mathrm{c}}$ Sección Genética Evolutiva, Instituto de Biología, Facultad de Ciencias, Universidad de la República, Montevideo, Uruguay \\ ${ }^{\mathrm{d}}$ Laboratory of Bioinformatics \& Biotechnology, Campus de Gurupi, Federal University of Tocantins, Gurupi, Tocantins, Brazil \\ ${ }^{\mathrm{e}}$ Laboratório de Virologia, Departamento de Microbiologia, Imunologia e Parasitologia, Instituto de Ciências Básicas da Saúde (ICBS), Universidade Federal do Rio \\ Grande do Sul (UFRGS), Rio Grande do Sul, Brazil \\ ${ }^{\mathrm{f}}$ Veterinary Virology and Animal Viral Diseases, Fundamental and Applied Research on Animal Health center and Faculty of Veterinary Medicine, University of Liège, \\ Liège, Belgium \\ ${ }^{g}$ Cátedra de Inmunogenética, Facultad de Ciencias Exactas, Químicas y Naturales, Universidad de Morón, Morón, Buenos Aires, Argentina
}

\section{A R T I C L E I N F O}

\section{Keywords:}

BoHV-1

BoHV-5

Natural recombination

Whole-genome

\begin{abstract}
A B S T R A C T
Bovine alphaherpesviruses 1 and 5 (BoHV-1 and BoHV-5) are closely related viruses that co-circulate in South America and recombine in the field. The complete genomes of three natural $\mathrm{gB}$ gene recombinant viruses between BoHV-1 and BoHV-5 were obtained by Illumina next-generation sequencing. Complete genome sequences of the three recombinant strains (RecA1, RecB2, and RecC2) have a similar size of approximately $138.3 \mathrm{~kb}$ and a GC content of 75\%. The genome structure corresponds to herpesvirus class D, with 69 open reading frames (ORFs) arranged in the same order as other bovine alphaherpesviruses related to BoHV-1. Their genomes were included in recombination network studies indicating statistically significant recombination evidence both based on the whole genome, as well as in the sub-regions. The novel recombinant region of $3074 \mathrm{nt}$ of the RecB2 and RecC2 strains includes the complete genes of the myristylated tegument protein (UL11) and the glycoprotein M (UL10) and part of the helicase (UL9) gene, and it seems to have originated independently of the first recombinant event involving the $\mathrm{gB}$ gene. Phylogenetic analyzes performed with the amino acid sequences of UL9, UL 10 , and UL11 indicated that RecB2 and RecC2 recombinants are closely related to the minor parental virus (BoHV-1.2b). On the contrary, RecA1 groups with the major parental (BoHV-5), thus confirming the absence of recombination in this region for this recombinant. One breakpoint in the second recombinant region lies in the middle of the UL9 reading frame, originating a chimeric enzyme half encoded by BoHV-5 and BoHV-1.2b parental strains. The chimeric helicases of both recombinants are identical and have 96.8 and $96.3 \%$ similarity with the BoHV-5 and BoHV-1 parents, respectively. In vitro characterization suggests that recombinants have delayed exit from the cell compared to parental strains. However, they produce the similar viral titer as their putative parents suggesting the accumulation of viral particles for the cell exit delayed on time. Despite in vitro different behavior, these natural recombinant viruses have been maintained in the bovine population for more than 30 years, indicating that recombination could be playing an important role in the biological diversity of these viral species. Our findings highlight the importance of studying whole genome diversity in the field and determining the role that homologous recombination plays in the structure of viral populations. A whole-genome recombinant characterization is a suitable tool to help understand the emergence of new viral forms with novel pathogenic features.
\end{abstract}

\footnotetext{
* Corresponding author at: Instituto de Virología e Innovaciones Tecnológicas IVIT (INTA-CONICET), Castelar, Buenos Aires, Argentina.

E-mail address: maidana.silvina@inta.gob.ar (S.S. Maidana).

1 These authors contributed equally to this work.
} 


\section{Introduction}

Bovine alphaherpesviruses 1 (BoHV-1) and 5 (BoHV-5) are two closely related alphaherpesviruses that infect cattle. The viral structure consists of a core containing linear double-stranded DNA, an icosahedral capsid, an amorphous-appearing material - the tegument -, and a phospholipid envelope containing viral glycoprotein spikes on its surface (Del Medico Zajac et al., 2010). BoHV-1 and BoHV-5 have a 'D' type genome arrangement, consisting of a unique long fragment (UL) and a unique short fragment (US) flanked by terminal and internal repeat sequences (Del Medico Zajac et al., 2010). Virion DNA includes equimolar amounts of DNA molecules differing in the US orientation relative to the UL region. At least in BoHV-1, low levels (5\%) of genomes have the UL segment in an inverted orientation (Schynts et al., 2003). These data obtained for BoHV-1 can reasonably be extrapolated to the BoHV-5 genome. The BoHV-5 genome is 137,821 base pairs (bp) long and is approximately $2 \mathrm{~kb}$ longer than the BoHV-1 genome, with a G + C base composition of 75\% (Delhon et al., 2003). The BoHV-5 genome contains 70 genes common to BoHV-1 but lacks a homolog of UL 0.5 (Delhon et al., 2003). The BoHV-5 genome encodes ten glycoproteins, namely, gK (UL53), gC (UL44), gB (UL27), gH (UL22), gM (UL10), gL (UL1) in the UL region, and gG (US4), gD (US6), gI (US7) and gE (US8) in US region (Delhon et al., 2003). Viral glycoproteins play important roles in virulence by mediating virion attachment and entry into the host cell, fusion, and cell-to-cell spread (Mettenleiter, 2003). The evolution of many viruses in the Alphaherpesvirinae subfamily has been attributed, in part, to the process of recombination. Recombination contributing to the evolution and diversity of alphaherpesviruses is particularly important as these viruses have a DNA polymerase with a highly efficient proof-reading and exonuclease activity that is associated with lower nucleotide substitution rates (Javier et al., 1986; Loncoman et al., 2017; Thiry et al., 2006). Early studies on alphaherpesvirus recombination used strain virulence as a marker to detect recombinants (Wildy, 1955). More recent analyses have been performed using polymerase chain reaction-restriction fragment length polymorphism (PCR-RFLP), gene deletion mutants, PCR hydrolysis probe assays, and phylogenetic incongruence of partial genomic regions (Del Medico Zajac et al., 2011; Dohner et al., 1988; Glazenburg et al., 1994; Henderson et al., 1990; Javier et al., 1986; Maidana et al., 2017; Muylkens et al., 2009; Norberg et al., 2004; Sakaoka et al., 1994; Schynts et al., 2003). Advances in next-generation sequencing of complete viral genomes permit the study of recombination in alphaherpesviruses that affects animals and humans, including herpes simplex virus 1 (HSV-1), varicella-zoster virus (VZV), infectious laryngotracheitis virus (ILTV) (Kolb et al., 2013; Lee et al., 2011; Norberg et al., 2006; Peters et al., 2006) and Equine herpesvirus 1 and 4 (Vaz et al., 2016). Such studies have improved our understanding of the role of recombination in the natural evolution of alphaherpesviruses. Our group provided the first evidence of natural interspecies recombination between two related ruminant alphaherpesviruses (BoHV-1 and BoHV-5) (Maidana et al., 2017). This previous study was performed using partial sequences of a few genes and in vitro assay that evidenced a delay in cell-cell dispersion that could not be associated with the recombination event involving the UL27 gene. Therefore, this study aimed to determine the full genome sequences of three natural recombinant viruses between BoHV-1 and BoHV-5 isolates from Argentina, compare them with other published ruminant herpesviruses sequences, complete the in vitro characterization and investigate the homologies of the proteins involved in recombination events.

\section{Materials and methods}

\subsection{Virus strains and propagation in cell culture}

All strains (Table 1) were propagated in Madin Darby bovine kidney (MDBK) cells, and viral stocks were produced after infection of MDBK at a low multiplicity of infection (MOI) as previously described (Maidana
Table 1

XXX.

\begin{tabular}{|c|c|c|c|c|}
\hline Viruses & Strain & Subtype & $\begin{array}{l}\text { GenBank } \\
\text { Accession } \\
\text { number }\end{array}$ & Ref. \\
\hline $\begin{array}{l}\text { BoHV- } \\
5\end{array}$ & $\begin{array}{l}2010^{*}=\text { Possible } \\
\text { parental (P2) }\end{array}$ & a & - & $\begin{array}{l}\text { Maidana } \\
\text { et al. (2018) }\end{array}$ \\
\hline \multirow[t]{4}{*}{$\begin{array}{l}\text { BoHV- } \\
1\end{array}$} & $\begin{array}{l}688 / 10^{*}=\text { Possible } \\
\text { parental (P1) }\end{array}$ & $1.2 \mathrm{~b}$ & - & $\begin{array}{l}\text { Maidana } \\
\text { et al. (2013) }\end{array}$ \\
\hline & $\begin{array}{l}\text { A663= Double } \\
\text { recombinant (RecB2) }\end{array}$ & $\mathrm{b}$ & MW829288 & $\begin{array}{l}\text { Carrillo et al. } \\
\text { (1983) }\end{array}$ \\
\hline & $\begin{array}{l}166 / 84^{*}=\text { Double } \\
\text { recombinant }(\text { RecC } 2)\end{array}$ & $\mathrm{b}$ & MZ364295 & $\begin{array}{l}\text { Maidana } \\
\text { et al. (2011) }\end{array}$ \\
\hline & $\begin{array}{l}674 / 10^{*}=\text { single } \\
\text { recombinant }(\operatorname{Rec} A 1)\end{array}$ & $\mathrm{b}$ & MZ420492 & $\begin{array}{l}\text { Maidana } \\
\text { et al. (2013) }\end{array}$ \\
\hline
\end{tabular}

Bovine alphaherpesvirus isolates used in this study.

: Field isolates with low passage number used in vitro assays.

et al., 2017).

\subsection{DNA purification and Illumina sequencing}

Viral DNA was extracted from $200 \mu \mathrm{L}$ suspensions of culture fluid (QIAamp viral DNA kit; Qiagen, Hilden, Germany) according to the manufacturer's instructions. The Nextera DNA Flex Library Preparation kit (Illumina, USA) was used for library preparation. The libraries were purified with AMPure XP (Benchman Coulter, USA) and quantified using a Qubit dsDNAHS assay kit (Invitrogen, USA). The quality and length of the library were assessed on a Fragment Analyzer 5200 system (Agilent Technologies, USA) using the Standard Sensitivity NGS Analysis Kit (Agilent Technologies, USA). Whole-genome sequencing was performed on an Illumina MiniSeq (Illumina, USA) platform (Facultad de Ciencias, Uruguay) using MiniSeq ${ }^{\mathrm{TM}}$ Mid Output Reagent Cartridge (300-cycles, paired-end reads).

\subsection{Genome assembly and annotation}

Adapter/quality trimming and raw data filtering were performed with BBDuk, and clean reads were mapped to the consensus genome using Geneious Prime 2020.1.2 (https://www.geneious.com). Consensus genomes were obtained and annotated using the complete reference genome of the bovine herpesvirus 5 strain SV507/99 (Accession: NC_005261.3 GI: 1,417,992,657).

\subsection{Genome sequence analysis}

\subsubsection{Possibility of recombination between $\mathrm{BoHV}-1$ and 5 strains}

Alignments of the complete genome sequences of the BoHV-1, BoHV5 , Bubaline alphaherpesvirus 1 , and caprine alphaherpesvirus- 1 , as well as the separate UL, US, and IR regions, were prepared using the Multiple Alignment with Fast Fourier Transformation (MAFFT) (Katoh and Standley, 2013).

Recombination networks on alignments of the whole genome and the sequences in different sub-regions (UL, IR, and US) of the 18 strains (the GenBank accession number below) were performed by using SplitsT (Huson, 1998). Statistical analysis of the recombination networks was generated by using the Phi test.

The sequences of the following ruminant alphaherpesvirus strains or isolates (with GenBank accession numbers) were included in the analysis: KY559403, NC_005261, KY549446, KU198480, AY261359, MG407780, MG407781, JX898220, KM258882, H598936, KM258881, KM258883, KM258880, NC_043054, BoHV-5 strain 2010, BoHV-5 strain A663 (RecB2)(MW829288), BoHV-5 strain 166/84 (RecC2) (MZ364295), BoHV-5 strain 674/10 (RecA1)(MZ420492).

\subsubsection{Recombination analysis}

Recombination analyses were performed using RDP, GENECONV, 
3Seq, SiScan, Chimarea, MaxChi, and Bootscan within RDP4 V 4.83. The same alignments were used to visualize breakpoint distribution plots to determine patterns and recombination hot spots. To further analyze the possibility of recombination, bootscan analysis was generated to detect the crossover points for recombination events of selected sequences as representatives of different clusters using Simplot (Lole et al., 1999).

\subsubsection{Phylogenetic analyses}

Nucleotide sequences were aligned using MAFFT v. 7.157b (Katoh and Standley, 2013). Individual ORFs were extracted and then translated using EMBOSS Transeq (http://www.eb i.ac.uk/Tools/st/emboss_transeq/), and the resulting amino acid sequences were aligned using MAFFT v. 7.157b (Katoh and Standley, 2013). Maximum likelihood (ML) phylogenetic trees were constructed using PhyML v. 3.1 (Guindon et al., 2010) under the general time-reversible substitution model. One hundred bootstrap replicates were conducted to assess statistical support for the tree topology.

\subsection{Viral growth kinetic}

To perform one-step kinetics, MDBK monolayers grown in $60 \mathrm{~mm}$ culture dishes were inoculated with 2010 BoHV-5 (P2), 688/10 BoHV-1 (P1), as the wild type strain. RecA1, RecB2, and RecC2 recombinant strains at MOI 5. Infected cells were incubated at $4{ }^{\circ} \mathrm{C}$ for $2 \mathrm{~h}$ to synchronize virus adsorption. Then, cells were incubated at $37^{\circ} \mathrm{C}$ for $2 \mathrm{~h}$ and treated with low $\mathrm{pH}$ solution $(40 \mathrm{mM}$ citric acid, $10 \mathrm{mM} \mathrm{KCl}$, $135 \mathrm{mM} \mathrm{NaCl}$ ) for $2 \mathrm{~min}$ to inactivate the remaining extracellular virus. Monolayers were rinsed with PBS, EMEM $2 \%$ FCS was added, and the dishes were incubated at $37{ }^{\circ} \mathrm{C}$. The extracellular and intracellular fractions were obtained at $0 ; 3 ; 6 ; 9 ; 12 ; 15 ; 18,21$ and 24 h postinfection (hpi). These fractions were titrated twice on MDBK monolayers in duplicate, and viral titers were calculated by the Reed and Muench method (Ramakrishnan, 2016).

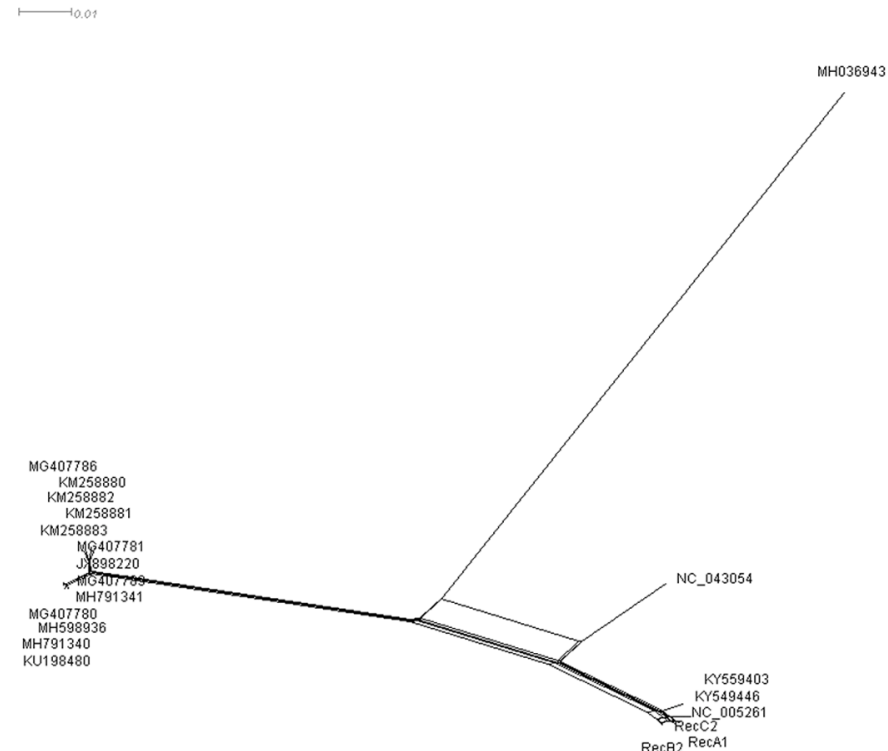

(a)

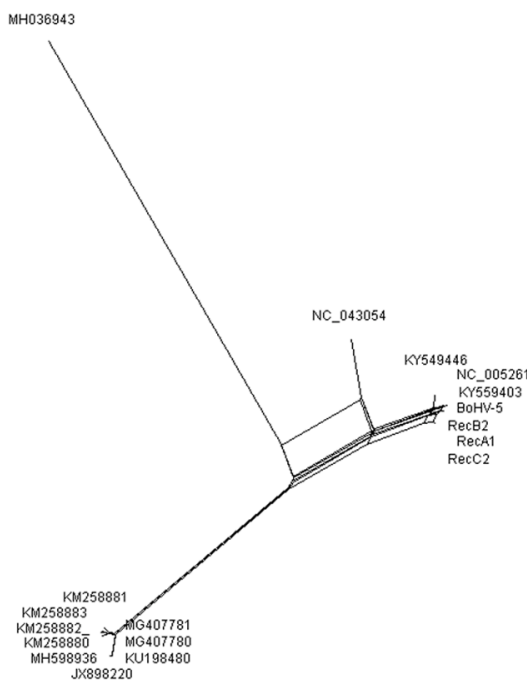

(b)

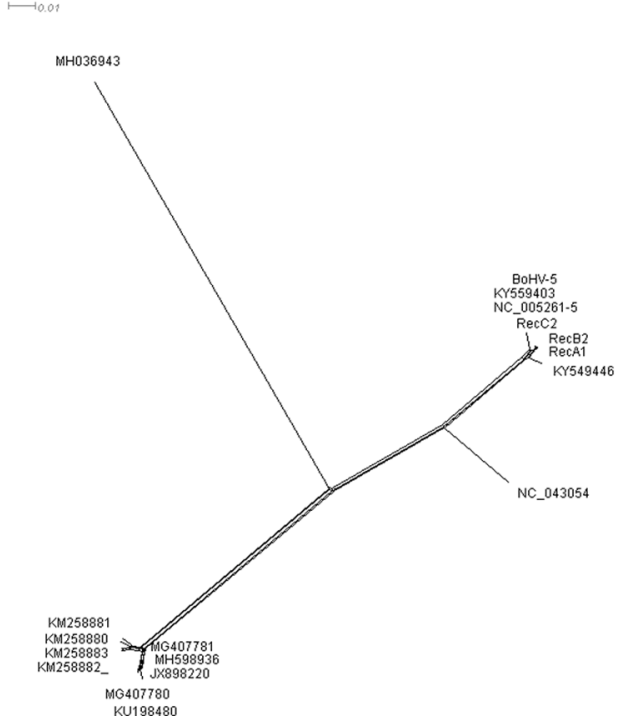

(c) (d)

Fig. 1. Recombination network trees generated from BoHV nucleotide alignments using SplitsTree4. (a) Complete genome sequences, (b) UL region, (c) US region and (d) repeat region. The multiple reticulate networks indicate recombination events between the different isolates. The bar indicates the rate of evolution in sequence substitutions per site. The Phi test for detecting recombination, as implemented in SplitsTree4, was highly significant for all alignments analyzed. 


\section{Result}

\subsection{Genome sequencing}

We obtained three complete genomes using Illumina next-generation sequencing. Genomes were obtained with good average coverage ( $>1000)$ and submitted to GenBank. Complete genome sequences of RecA1, RecB2, and RecC2 strains have a similar size of approximately $138.3 \mathrm{~kb}$ and a GC content of $75 \%$.

The genome structure corresponds to the herpesvirus class $\mathrm{D}$, consisting of a long and a short unique region (UL and US), flanked by inverted repeats (TRL/IRL and IRS/TRS). They have 69 open reading frames (ORFs) arranged in the same order as other bovine alphaherpesviruses. Genomes have 98.3-99.3\% similarity with the BoHV-5 and $81.6-82.5 \%$ similarity with the BoHV-1.

\subsection{Recombination network}

Recombination network analysis of the whole genome and different genomic sub-regions of the 18 strains were performed (Fig. 1). A total of 22,115 informative sites were found in the whole genome of the 18 strains, and the phi test shows statistically significant evidence for recombination ( $p=0.0$ ) (Fig. 1a). The recombination events span the UL region (10,528 informative sites, $p=0.0)$ (Fig. 1b), the US region (4275 informative sites, $p<0.001$ ) (Fig. 1c) and the IR region (3365 informative sites, $p<0.001$ ) (Fig. 1d)

\subsection{Interspecific recombination}

Six algorithms detected a recombinant event involving the $\mathrm{gB}$ glycoprotein coding region (first recombination event reported) in the three strains (RecA1, RecB2, and RecC2). Seven RDP4 algorithms identified an additional recombinant event (second recombination event reported here) in RecB2 and RecC2 (Fig. 2). Both recombination events involved the same parents (Table 2) and were in the UL region. The second recombination event involves 3074 nt $(85,366-88,502$ according to BoHV-5 KY5494461) and includes coding sequences of the myristylated tegument protein (UL11), a membrane glycoprotein $\mathrm{gM}$ (UL10), and the origin of replication binding helicase (UL9). The breakpoints in this second recombinant region are embedded in long fragments of high sequence identity with the putative parental genomes.
Table 2

Recombination breakpoint analysis of full BoHV-5 recombinant genome sequences.

\begin{tabular}{cllll}
\hline $\begin{array}{l}\text { Recombinant } \\
\text { strain }\end{array}$ & Region & $\begin{array}{l}\text { Breakpoint } \\
\text { beginning }\end{array}$ & $\begin{array}{l}\text { breakpoint } \\
\text { ending }\end{array}$ & $\begin{array}{l}\text { Methods of } \\
\text { recombination } \\
\text { detection }\end{array}$ \\
\hline $\begin{array}{c}\text { RecA1, RecB2 } \\
\text { and RecC2 }\end{array}$ & UL27 & 54,997 & 57,242 & R, G, B, M, C, S \\
RecB2, RecC2 & $\begin{array}{l}\text { UL11, } \\
\text { UL10, }\end{array}$ & 85,366 & $\mathbf{8 8 , 5 0 2}$ & R, G, B, M, C, S, T \\
& UL9 & & & \\
\hline
\end{tabular}

R: RDP, G: GENECOV, B: BootScan, M: MaxChi, C: Chimaera, S: SiScan, T: 3Seq.

\subsection{Recombination and amino acid studies}

Phylogenetic analysis of the second recombination event showed that UL11, UL10, and UL9 regions are closely related to the minor parent (BoHV-1.2b) in RecB2 and RecC2 strains. On the contrary, the UL11, UL10, and UL9 regions cluster with the major parent (BoHV-5) in the RecA1 strain. The latter confirms RecA1 lacks the second recombination event (Fig. 3).

The gM in RecB2 and RecC2 are almost $100 \%$ similar to BoHV-1.2b gM (Table 3). The recombination breakpoint converts the UL9 helicase into a chimera with 396 aa encoded by BoHV-1 and 428 aa by BoHV-5 (Table 3). The chimeric helicases of both recombinants are identical and have 96.8 and $96.3 \%$ similarity with the BoHV-5 and BoHV-1 parents, respectively.

\subsection{In vitro characterization}

In the one-step kinetics, the viral titers reached by both fractions indicate that the production of infectious viral particles was similar for the recombinant strains and the possible parents at all times tested (Fig. 4), reaching the maximum peak at $15,18 \mathrm{~h}$ post-infection (hpi) (10 $\left.{ }^{8,0} \mathrm{DICT}_{50} / \mathrm{ml}\right)$ for the RecB2 and RecC2 strains and at $21 \mathrm{hpi}\left(10^{7,5}\right.$ $\mathrm{DICT}_{50} / \mathrm{ml}$ ) for the P1 putative parental strain (Fig. 4).

The egress of infectious viral particles to the extracellular medium occurred first in P1 and P2 parental strains, being detected at $3 \mathrm{hpi}\left(10^{2,2}\right.$ $\mathrm{DICT}_{50} / \mathrm{ml}$ and $10^{2} \mathrm{DICT}_{50} / \mathrm{ml}$, respectively) (Fig. $4 \mathrm{c}$ ). The egress of the recombinant RecB2 and RecC2 strain strains was detected at $6 \mathrm{hpi}$ (Fig. 4A) and in strain RecA1 at 9 hpi (Fig. 4B). Higher titers in the

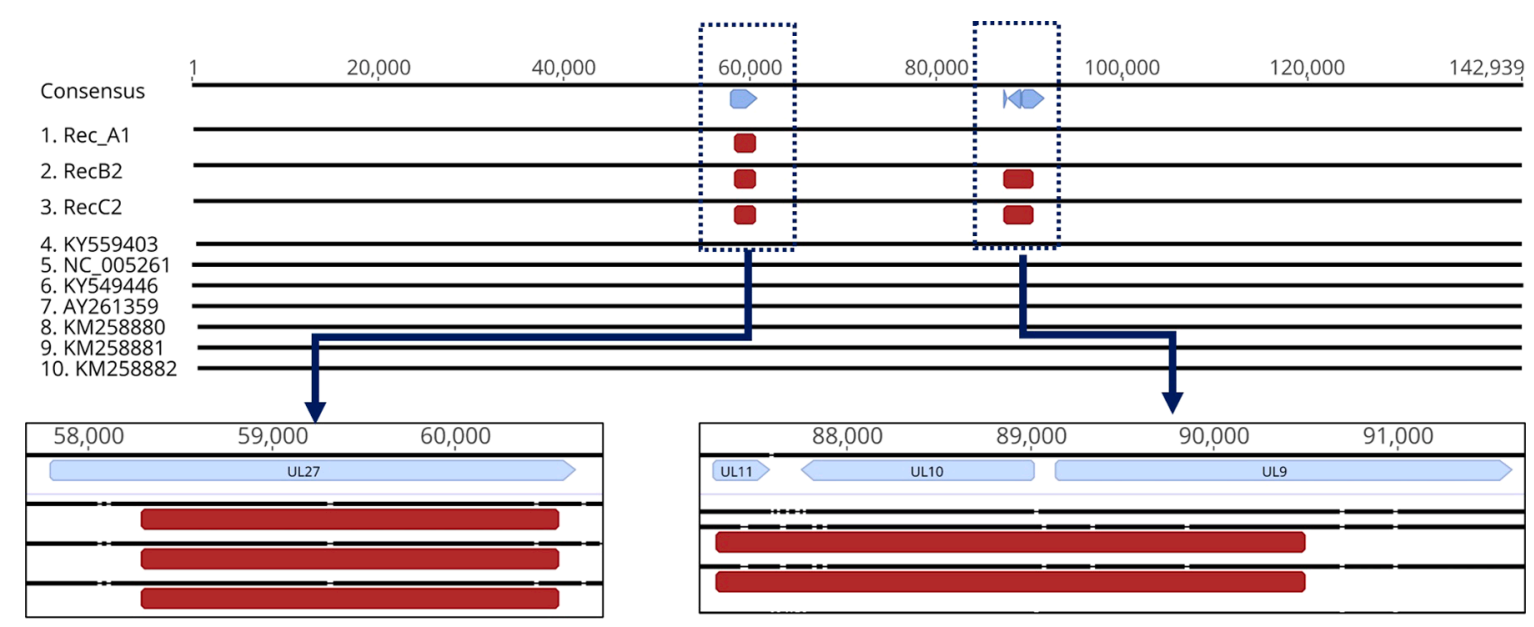

\section{Recombination event I}

\section{Recombination event II}

Fig. 2. Graphical representation of the genomes of three recombinant strains isolated and sequenced in this study. In A the complete genome alignment of the 3 recombinant genomes is shown along with 4 BoHV-5 genomes and 2 BoHV-1.2 genomes. The region of the two recombination events marked in red is shown, in the consensus sequence the genes involved in each event. The genomic sequences used were for BoHV-5: KY559403, NC_005261, KY549446, AY261359 and for BoHV1.2: KM258880, KM258881, KM258882 (For interpretation of the references to color in this figure legend, the reader is referred to the web version of this article). 


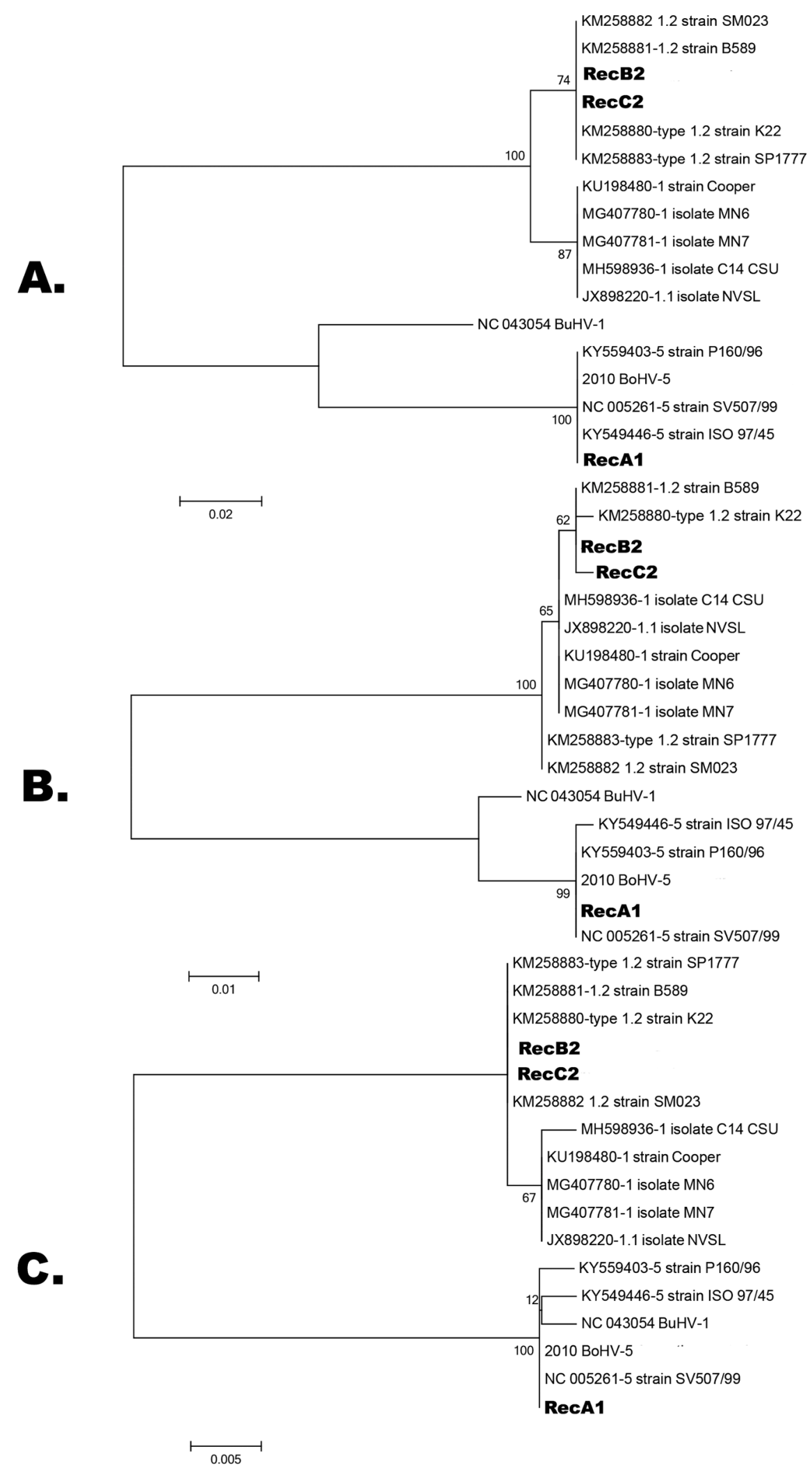

Fig. 3. Amino acid phylogenetic analysis based on A: myristylated tegument protein (UL11), B: M glycoprotein (UL10) and C: Helicase (UL9). Maximum likelihood phylogenetic trees were generated using amino acid alignments. One hundred bootstrap replicates were used to assess the significance of the tree topologies and the number of replicate trees containing each specific branch in the consensus tree is shown next to that branch. Two recombinant viruses (RecB2 and RecC2) show clustering with BoHV-1.2 for three analyzed proteins. The RecA1 recombinant strain always groups with the BoHV-5 in these three studied proteins. 
Table 3

Homology of amino acid sequences of the origin binding helicase protein and glycoprotein M.

\begin{tabular}{lllll}
\hline \multirow{2}{*}{ \% identity aa } & \multicolumn{2}{l}{ Origin binding helicase } & gM & \\
& BoHV-5a & BoHV-1.2b & BoHV-5a & BoHV-1.2b \\
\hline RecB2 & 96.8 & 96.3 & 86.8 & 100 \\
RecC2 & 96.8 & 96.3 & 86.8 & 99,7 \\
RecA1 & 99.8 & 93.3 & 100 & 86,8 \\
\hline
\end{tabular}

Our findings support that the recombinant event involving the UL27 gene produces the first generation recombinants in the RecA1, RecB2 and RecC2 strains. In two of these three primary recombinants (RecB2 and RecC2), subsequent coinfection and recombination with BoHV-1.2b generated the second generation recombinants. These recombinants are stable since they have been circulating in the bovine population for more than 30 years.

In several in vivo and in vitro experimental studies where related viruses with high genetic similarity were co-inoculated, a high frequency of recombinant progeny was determined (Loncoman et al., 2017b, 2017a; Meurens et al., 2004). The BoHV-1 and 5 recombinants detected and obtained in vitro by Meurens et al. (2004). Meurens et al. (2004), showed only one recombination point, different from what occurs in the natural recombinant reported here. This observation coud explain the theory of double-strand break repair model, the current model of homologous recombination that might occur during herpesvirus replication (d'Offay et al., 2019). Unlike what happened with the first recombination event described in Maidana et al. (2017), the second recombination event occurs within the longest fragments of sequence homology where the breakpoint was within a constant 454 and $113 \mathrm{nt}$ detected in both recombination sites. These data also reinforce the theory of different origins in constructing the current genomic background of these three recombinant strains. Previously reported that short homologous sequences were sufficient as templates for recombination occurrence in nature (Maidana et al., 2017). In light of these new results we demonstrate that both short and long homologous fragment types can be template to generate recombinants.

The recombinant fragment described in RecB2 and RecC2 involves the UL11 gene that encodes a myristylated tegument protein, the UL10 gene that encodes a membrane glycoprotein $(\mathrm{gM})$, both proteins with a $100 \%$ aa similarity for the minor parental BoHV-1.2b; it also includes a part of the UL9 gene that codes for an origin of replication binding helicase. Phylogenetic analyzes indicate that these proteins grouped with the minor parental virus (BoHV-1.2b). Although the breakpoint within the reading frame of the helicase originates a chimeric enzyme encoded by BoHV-5 and BoHV-1.2b in the same proportion, the helicase is one of the most conserved proteins in these viruses. The chimeric protein reported here showed $93,2 \%$ the amino acid similarity respect of parental viruses enzymes (Table 3). A natural double recombinant between a wild type BoHV-1 strain and a BoHV-1 vaccinal strain has a breakpoint in the UL9 of the UL region and is then close to the position of the second recombinant event in the RecB2 and RecC2 strains (d'Offay et al., 2019)

The in vitro behavior of the recombinant strains and previously reported results (Ladelfa et al., 2011; Maidana et al., 2017) suggests that recombinants have decreased capacities of cell egress compared to parental strains. Recombinant viruses have delayed cell exit, with high titers in the intracellular fraction for recombinants compared to their parents, indicating an accumulation of viral particles. RecA1 is the most delayed strain compared to RecB2 and RecC2, but the last two display higher intracellular titers. In vitro evaluation of the RecB2 (A663) strain using the human neuroblastoma cell line SH-SY5Y showed a similar intracellular accumulation of viral particles, but the authors attributed it to a slow replicative cycle (Rosales et al., 2020). However, both results show here and in Ladelfa et al. (2011) indicate only the accumulation of intracellular particles and the consequent exit delay without a marked decrease in viral titer compared to parental ones. The double recombinants leave the cell first and would have a greater replicative efficiency, evidence by reaching titres similar to RecA1 at $24 \mathrm{~h}$. The latter also has a delayed exit, but infects a greater number of cells in less time, generating larger plaque sizes than RecB2 and RecC2 (Maidana et al., 2017). In general, whether they are double or single recombinants, they achieve similar viral titers, probably because they use alternative routes to achieve the same levels of viral production compared to parental viruses. Pannhorst et al. (2018) demonstrated through the generation of different mutants that the number of infectious particles released was not affected because the viruses triggered another gM-independent signaling pathway, a result that coincides with our observations in wild-type mutant viruses (Pannhorst et al., 2018).

RecB2 shows light different pathogenesis than BoHV-5 (strain N569) in the bovine host (Ladelfa et al., 2011). These pathogenicity differences were initially attributed to the adaptation of the inoculo of parent strain to cell cultures but now may be explained by the occurrence of two recombinations in RecB2. Further studies, including confirmation of the delayed exit in primary cells of these recombinant viruses and testing in the natural host of a few passages of the possible parental viruses, are needed to understand the biological properties of the recombinants.

To understand the evolutionary processes that may have occurred in natural recombinant isolates, we performed a worldwide genome comparison. Recombinant networks based on the whole genome and the analyses in sub-regions (UL, IR, and US) indicated statistically significant recombination events. This study constitutes the first characterization of the recombination pattern in the complete genome of bovine alphaherpesviruses natural recombinant. Similar analyses have been reported in avian (He et al., 2018) and equine alphaherpesviruses (Bryant et al., 2018), evidencing the need to analyze complete genomes for the proper characterization of the recombinants.

The genomic homology of ruminant alphaherpesviruses (Thiry et al., 2011); the cattle husbandry management favoring mixed productions in Argentina (Maidana et al., 2018, 2014); the lack of mandatory vaccination schedule for BoHV-1 the scarce management under welfare standards added to farming intensification causes immunosuppression due to stress and reactivation from latency (Favier et al., 2012) increase the risk of co-circulation of different viral types and subtypes favoring homologous recombination. The evolution of alphaherpesviruses, including interspecific recombination and inter-host jumps, favors the appearance of emerging recombinant viruses that might infect different hosts.

\section{Conclusion}

We Identify consecutive recombination events different from those already reported, noting that double recombinants could persist in the field. Despite showing modified characteristics of in vitro replication, these field recombinants were maintained in the bovine population for more than 30 years, indicating that recombination has played an important role in the natural variability of these viral species. Diversity will allow the virus to increase or change virulence in the same host, enabling it to infect new tissues and establish new transmission routes that ensure persistence in the host population.

Our findings highlight the importance of studying using complete genome data to determine the role of homologous recombination in the diversity of natural viral populations. Furthermore, establishing the recombination impact could help understand viruses' evolutionary behavior and thus predict future threats to animal health.

\section{Funding}

This study was financially supported by the Agencia Nacional de Promoción Científica y Tecnológica (ANPyCT), Ministerio de Ciencia, Tecnología e Innovación Productiva, Argentina (Grant BID-PICT-2018 $\mathrm{N}^{\circ}$ 4349); The Genomic Platform in Facultad de Ciencias (Uruguay) was 
A

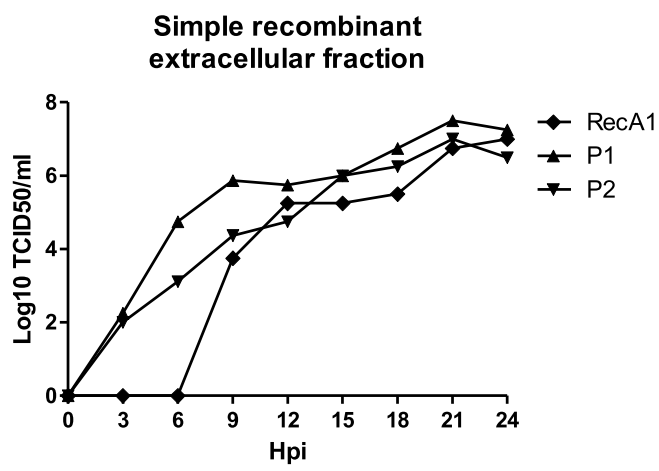

C
B

\section{Double recombinant viruses} extracellular fraction

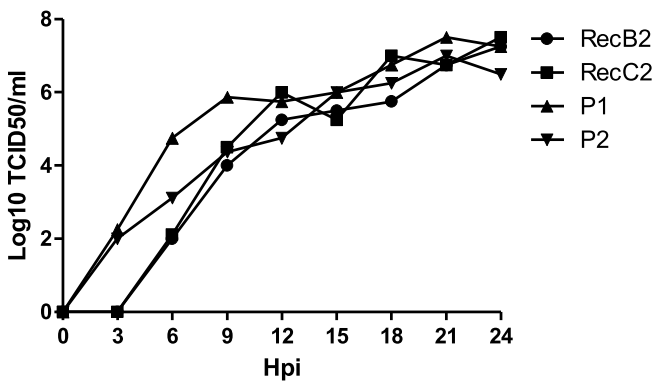

D
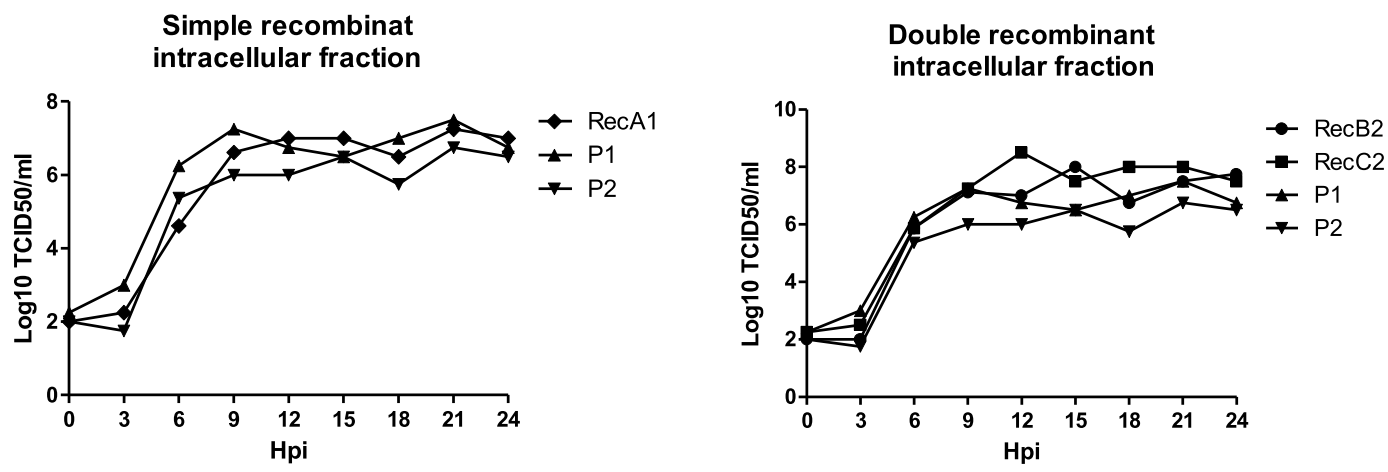

E

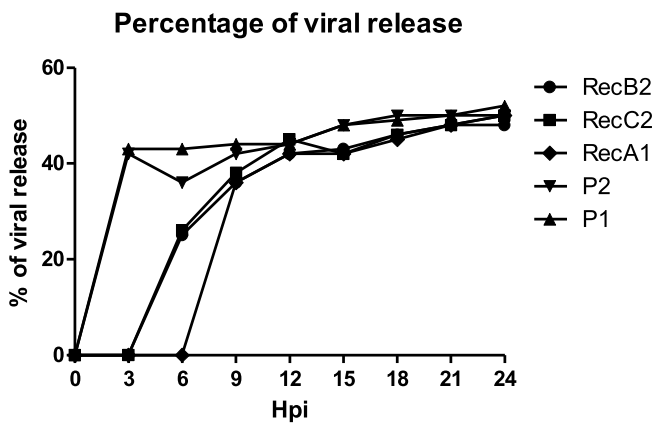

Fig. 4. One-step growth kinetics of possible parent (P1 BoHV-1 and P2 BoHV-5 strain) and recombinant strain (RecA1, RecB2, and RecB2 strains) (MOI 5). A and B: extracellular fraction viral titres. C and D: intracellular fraction viral titres. Viral titres are expressed as Log10 TCID50 ml. E: Percentage of viral release for possible parental and recombinant strains at MOI 5 release $=$ [extracellular $/$ (intracellular + extracellular) $].$ Hpi $=$ hours post-infection.

supported by the Comisión Sectorial de Investigación Científica (CSIC) (Grant CSIC Equipamiento, Responsable Dra. Yanina Panzera)

\section{Declaration of Competing Interest}

The authors declare there is no conflict of interest in the submission of this paper. 


\section{Acknowledgments}

We thank Natalia Bachir and Fatima Torales for the excellent technical help

\section{References}

Bryant, N.A., Wilkie, G.S., Russell, C.A., Compston, L., Grafham, D., Clissold, L., McLay, K., Medcalf, L., Newton, R., Davison, A.J., Elton, D.M., 2018. Genetic diversity of equine herpesvirus 1 isolated from neurological, abortigenic and respiratory disease outbreaks. Transbound. Emerg. Dis. 65, 817-832. https://doi. org/10.1111/tbed.12809.

Carrillo, B.J., Ambrogí, A., Schudel, A.A., Vazquez, M., Dahme, E., Pospischil, A., 1983. Meningoencephalitis caused by IBR virus in calves in Argentina. Zentralbl. Veterinarmed. B. 30, 327-332. https://doi.org/10.1111/J.1439-0450.1983. TB01852.X.

d'Offay, J.M., Fulton, R.W., Fishbein, M., Eberle, R., Dubovi, E.J., 2019. Isolation of a naturally occurring vaccine/wild-type recombinant bovine herpesvirus type 1 (BoHV-1) from an aborted bovine fetus. Vaccine 37, 4518-4524. https://doi.org/ 10.1016/j.vaccine.2019.06.059.

Del Medico Zajac, M.P., Ladelfa, M.F., Kotsias, F., Muylkens, B., Thiry, J., Thiry, E., Romera, S.A., 2010. Biology of bovine herpesvirus 5. Vet. J. 184, 138-145. https:// doi.org/10.1016/j.tvjl.2009.03.035.

Del Medico Zajac, M.P., Romera, S.A., Ladelfa, M.F., Kotsias, F., Delgado, F., Thiry, J., Meurens, F., Keil, G., Thiry, E., Muylkens, B., 2011. In vitro-generated interspecific recombinants between bovine herpesviruses 1 and 5 show attenuated replication characteristics and establish latency in the natural host. BMC Vet. Res. 7, 19. https:// doi.org/10.1186/1746-6148-7-19.

Delhon, G., Moraes, M.P., Lu, Z., Afonso, C.L., Flores, E.F., Weiblen, R., Kutish, G.F., Rock, D.L., 2003. Genome of bovine herpesvirus 5. J. Virol. 77, 10339-10347.

Dohner, D.E., Adams, S.G., Gelb, L.D., 1988. Recombination in tissue culture between varicella-zoster virus strains. J. Med. Virol. 24, 329-341.

Favier, P.A., Marin, M.S., Pérez, S.E., 2012. Role of bovine herpesvirus type 5 (BoHV-5) in diseases of cattle. Recent findings on BoHV-5 association with genital disease. Open Vet. J. 2, 46.

Glazenburg, K.L., Moormann, R.J., Kimman, T.G., Gielkens, A.L., Peeters, B.P., 1994. In vivo recombination of pseudorabies virus strains in mice. Virus Res. 34, 115-126.

Guindon, S., Dufayard, J.F., Lefort, V., Anisimova, M., Hordijk, W., Gascuel, O., 2010. New algorithms and methods to estimate maximum-likelihood phylogenies: assessing the performance of PhyML 3.0. Syst. Biol. 59, 307-321. https://doi.org/ 10.1093/sysbio/syq010.

He, L., Li, J., Zhang, Y., Luo, J., Cao, Y., Xue, C., 2018. Phylogenetic and molecular epidemiological studies reveal evidence of recombination among Marek's disease viruses. Virology 516, 202-209. https://doi.org/10.1016/j.virol.2018.01.019.

Henderson, L.M., Katz, J.B., Erickson, G.A., Mayfield, J.E., 1990. In vivo and in vitro genetic recombination between conventional and gene-deleted vaccine strains of pseudorabies virus. Am. J. Vet. Res. 51, 1656-1662.

Huson, D.H., 1998. Splitstree: analyzing and visualizing evolutionary data. Bioinformatics 14, 68-73. https://doi.org/10.1093/bioinformatics/14.1.68.

Javier, R.T., Sedarati, F., Stevens, J.G., 1986. Two avirulent herpes simplex viruses generate lethal recombinants in vivo. Science 234, 746-748.

Katoh, K., Standley, D.M., 2013. MAFFT multiple sequence alignment software version 7: improvements in performance and usability. Mol. Biol. Evol. 30, 772-780. https:// doi.org/10.1093/molbev/mst010.

Kolb, A.W., Ané, C., Brandt, C.R., 2013. Using HSV-1 genome phylogenetics to track past human migrations. PLOS One 8, e76267. https://doi.org/10.1371/journal. pone.0076267.

Ladelfa, M.F., Del Médico Zajac, M.P., Kotsias, F., Delgado, F., Muylkens, B., Thiry, J., Thiry, E., Romera, S.A., 2011. Comparative study on the in vitro and in vivo properties of two bovine herpesvirus- 5 reference strains. Acta Vet. Scand. 53, 37. https://doi.org/10.1186/1751-0147-53-37.

Lee, S.W., Devlin, J.M., Markham, J.F., Noormohammadi, A.H., Browning, G.F., Ficorilli, N.P., Hartley, C.A., Markham, P.F., 2011. Comparative analysis of the complete genome sequences of two Australian origin live attenuated vaccines of infectious laryngotracheitis virus. Vaccine 29, 9583-9587. https://doi.org/10.1016/ j.vaccine.2011.10.055

Lole, K.S., Bollinger, R.C., Paranjape, R.S., Gadkari, D., Kulkarni, S.S., Novak, N.G., Ingersoll, R., Sheppard, H.W., Ray, S.C., 1999. Full-length human immunodeficiency virus type 1 genomes from subtype C-infected seroconverters in India, with evidence of intersubtype recombination. J. Virol. 73, 152-160.

Loncoman, C.A., Hartley, C.A., Coppo, M.J.C., Vaz, P.K., Diaz-Méndez, A., Browning, G. F., Garcí, M., Spatz, S., Devlin, J.M., 2017a. Genetic diversity of infectious laryngotracheitis virus during in vivo coinfection parallels viral replication and arises from recombination hot spots within the genome. Appl. Environ. Microbiol. 83 https://doi.org/10.1128/AEM.01532-17.

Loncoman, C.A., Hartley, C.A., Coppo, M.J.C., Vaz, P.K., Diaz-Mendez, A., Browning, G. F., Lee, S.W., Devlin, J.M., 2017b. Development and application of a Taq Mansingle nucleotide polymorphism genotyping assay to study infectious laryngotracheitis virus recombination in the natural host. Proc. Natl. Acad. Sci. U. S. A. https://doi. org/10.1371/journal.pone.0174590.

Loncoman, C.A., Vaz, P.K., Coppo, M.J., Hartley, C.A., Morera, F.J., Browning, G.F., Devlin, J.M., 2017. Natural recombination in alphaherpesviruses: insights into viral evolution through full genome sequencing and sequence analysis. Infect. Genet. Evol. 49, 174-185. https://doi.org/10.1016/j.meegid.2016.12.022.

Maidana, S.S., Morano, C.D., Cianfrini, D., Campos, F.S., Roehe, P.M., Siedler, B., De Stefano, G., Mauroy, A., Thiry, E., Romera, S.A., 2013. Multiplex PCR followed by restriction length polymorphism analysis for the subtyping of bovine herpesvirus 5 isolates. BMC Vet. Res. 9, 111. https://doi.org/10.1186/1746-6148-9-111.

Maidana, S.S., Ladelfa, M.F., Pérez, S.E., Lomónaco, P.M., Del Médico Zajac, M.P., Odeón, A., Blanco Viera, J., Combessies, G., Fondevila, N., Palacios, M., Thiry, J., Muylkens, B., Thiry, E., Romera, S.A., 2011. Characterization of BoHV-5 field strains circulation and report of transient specific subtype of bovine herpesvirus 5 in Argentina. BMC Vet. Res. 7, 8. https://doi.org/10.1186/1746-6148-7-8.

Maidana, S.S., Craig, P.O., Craig, M.I., Ludwig, L., Mauroy, A., Thiry, E., Romera, S.A., 2017. Evidence of natural interspecific recombinant viruses between bovine alphaherpesviruses 1 and 5. Virus Res. 242, 122-130. https://doi.org/10.1016/j. virusres.2017.09.018.

Maidana, S.S., Destefano, G., Romera, S.A., Marin, M., Combessies, G., 2018. Bovine herpesvirus 1 (BoHV-1): Update of circulating strains in Argentina. Rev. Vet. 29, 52-56.

Maidana, S.S., Konrad, J.L., Craig, M.I., Zabal, O., Mauroy, A., Thiry, E., Crudeli, G., Romera, S.A., 2014. First report of isolation and molecular characterization of bubaline herpesvirus 1 (BuHV1) from Argentinean water buffaloes. Arch. Virol. 159, 2917-2923. https://doi.org/10.1007/s00705-014-2146-8.

Meurens, F., Keil, G.M., Muylkens, B., Gogev, S., Schynts, F., Negro, S., Wiggers, L., Thiry, E., 2004. Interspecific recombination between two ruminant alphaherpesviruses, bovine herpesviruses 1 and 5. J. Virol. 78, 9828-9836. https:// doi.org/10.1128/JVI.78.18.9828-9836.2004.

Muylkens, B., Farnir, F., Meurens, F., Schynts, F., Vanderplasschen, A., Georges, M., Thiry, E., 2009. Coinfection with two closely related alphaherpesviruses results in a highly diversified recombination mosaic displaying negative genetic interference. J. Virol. 83, 3127-3137. https://doi.org/10.1128/JVI.02474-08.

Norberg, P., Bergström, T., Rekabdar, E., Lindh, M., Liljeqvist, J.A., 2004. Phylogenetic analysis of clinical herpes simplex virus type 1 isolates identified three genetic groups and recombinant viruses. J. Virol. 78, 10755-10764. https://doi.org/ 10.1128/JVI.78.19.10755-10764.2004.

Norberg, P., Liljeqvist, J.A., Bergström, T., Sammons, S., Schmid, D.S., Loparev, V.N., 2006. Complete-genome phylogenetic approach to varicella-zoster virus evolution: genetic divergence and evidence for recombination. J. Virol. 80, 9569-9576. https://doi.org/10.1128/JVI.00835-06.

Pannhorst, K., Wei, H., Yezid, H., He, J., Chowdhury, S.I., 2018. Bovine herpesvirus 1U L 49.5 interacts with gM and VP22 to ensure virus cell-to-cell spread and virion incorporation: novel role for VP22 in gM-independent U L 49.5 virion incorporation. J. Virol. 92, e00218-e00240. https://doi.org/10.1128/jvi.00240-18.

Peters, G.A., Tyler, S.D., Grose, C., Severini, A., Gray, M.J., Upton, C., Tipples, G.A., 2006. A full-genome phylogenetic analysis of varicella-zoster virus reveals a novel origin of replication-based genotyping scheme and evidence of recombination between major circulating clades. J. Virol. 80, 9850-9860. https://doi.org/10.1128/ JVI.00715-06.

Ramakrishnan, M.A., 2016. Determination of 50\% endpoint titer using a simple formula. World J. Virol. 5, 85-86. https://doi.org/10.5501/wjv.v5.i2.85.

Rosales, J.J., Verna, A., Marin, M., Pérez, S., 2020. Bovine alphaherpesvirus type 5 replicates more efficiently than bovine alphaherpesvirus type 1 in undifferentiated human neural cells. Virus Res. 286 https://doi.org/10.1016/j.virusres.2020.198037.

Sakaoka, H., Kurita, K., Iida, Y., Takada, S., Umene, K., Kim, Y.T., Ren, C.S., Nahmias, A. J., 1994. Quantitative analysis of genomic polymorphism of herpes simplex virus type 1 strains from six countries: studies of molecular evolution and molecular epidemiology of the virus. J. Gen. Virol. 75, 513-527. https://doi.org/10.1099/ 0022-1317-75-3-513.

Schynts, F., Meurens, F., Detry, B., Vanderplasschen, A., Thiry, E., 2003. Rise and survival of bovine herpesvirus 1 recombinants after primary infection and reactivation from latency. J. Virol. 77, 12535-12542.

Mettenleiter, T.C., 2003. Pathogenesis of neurotropic herpesviruses: role of viral glycoproteins in neuroinvasion and transneuronal spread. Virus Res. 92, 197-206. https://doi.org/10.1016/S0168-1702(02)00352-0.

Thiry, E., Muylkens, B., Meurens, F., Gogev, S., Thiry, J., Vanderplasschen, A., Schynts, F., 2006. Recombination in the alphaherpesvirus bovine herpesvirus 1 . Vet. Microbiol. 113, 171-177. https://doi.org/10.1016/j.vetmic.2005.11.012.

Thiry, J., Dams, L., Muylkens, B., Thiry, E., 2011. Isolation of cervid herpesvirus 1 from the genital tract of a farmed red deer in Northern France. Vet. J. https://doi.org/ 10.1016/j.tvjl.2009.11.021.

Vaz, P.K., Job, N., Horsington, J., Ficorilli, N., Studdert, M.J., Hartley, C.A., Gilkerson, J. R., Browning, G.F., Devlin, J.M., 2016. Low genetic diversity among historical and contemporary clinical isolates of felid herpesvirus 1 . BMC Genom. 17, 704. https:// doi.org/10.1186/s12864-016-3050-2.

Wildy, P., 1955. Recombination with herpes simplex virus. J. Gen. Microbiol. 13, 346-360. https://doi.org/10.1099/00221287-13-2-346. 